\title{
Uma análise da vida cotidiana e dos espaços domésticos de Atenas (séc. VI-IV a.C.)
}

\author{
An analysis about the daily life and the domestic spaces at Athens
}

$\left(6^{\text {th }}-4^{\text {th }}\right.$ centuries $\left.B C\right)$

\section{Edson Moreira Guimarães Neto*}

Resumo: Neste artigo, tentaremos observar e analisar a vida cotidiana dentro do contexto dos espaços domésticos e como as esposas legítimas e as cortesãs (inclusive na qualidade de agentes rituais) conviviam com os cidadãos atenienses nesses lugares. Por meio do trabalho com a documentação proposta, tomaremos as esferas de convivência e os processos de interação social intragrupais e intergrupais para analisar os pontos similares entre as vidas das atenienses e das hetaírai, e assim elucidarmos como o discurso em torno da matriz feminina era operado para fundamentar a construção conceitual da vida doméstica.

\begin{abstract}
In this article, we will try to observe and analyze everyday life within the context of domestic spaces and how the lawful wives and courtesans (even as ritual agents) lived with the Athenian citizens in these places. Through working with the proposed documentation, we will take the spheres of coexistence and intragroup and intergroup social interaction processes to analyze similar points between the lives of Athenian women and hetairai, and thus elucidate how the discourse around the feminine matrix was operated for the conceptual construction of domestic life.
\end{abstract}

\author{
Palavras-chave: \\ Atenas; \\ Gênero; \\ Cotidiano; \\ Espaço; \\ Mulheres.
}

* Doutor em História Comparada pelo Programa de Pós-graduação em História Comparada (PPGHC) da Universidade Federal do Rio de Janeiro (UFRJ). 


\section{1 investigação sobre a construção social e o uso do espaço urbano não é uma 1 área de estudos nova e já foi bastante discutida tanto em nível empírico quanto 1 teórico, relacionando cidades antigas, medievais e modernas (FOXHALL; NEHER,} 2013, p. 5). ${ }^{1}$ Estudos mostram que o espaço em locais urbanos era bastante matizado, multidimensional e polivalente, variando em tamanho desde o espaço pessoal do corpo até a concepção de espaços concretos da paisagem urbana.

Os espaços mais informais dos jardins, sacadas, janelas e telhados podem ser arquitetonicamente marginalizados, entretanto, são fundamentais para as interações. O uso de tais espaços é genderizado, e isso pode ser notado mais claramente quando observamos as estruturas que delineiam os limites. Além disso, a proximidade entre as diversas construções e as dimensões complexas das cidades incorporavam e encorajavam uma experiência sensorial mais ampla acerca da vida social nas comunidades urbanas, incluindo sons, odores e tatos, além da visão (Demóstenes, Contra Neera, 47, 53-7; FOXHALL; NEHER, 2013, p. 7). Era importante observar e ser observado(a) e, talvez, estar um passo à frente dos outros. Ver (e ouvir) era tão importante quanto ser visto.

A arquitetura das residências atenienses sugere um grande empenho em isolar o mundo do interior do oîkos daquele da cidade que estava além de suas paredes. $O$ acesso à residência era feito por uma porta individual para a rua. A comunicação com essa porta e o restante dos cômodos era feita através de um pátio na parte central ou ao sul da residência, que também era utilizado para a locomoção interna, como podemos observar na planta ilustrada na Figura 1.

\footnotetext{
${ }^{1} \mathrm{O}$ espaço assim compreendido é uma dimensão da realidade, que pode ser utilizada de diversas maneiras. Desse modo, é necessário deixar claro que o espaço social está contido no espaço geográfico, criado originalmente pela natureza e transformado continuamente pelas relações sociais, que produzem diversos outros tipos de espaços materiais e imateriais, tais como: políticos, culturais e econômicos. O espaço é multidimensional e, portanto, é formado pelos elementos da natureza e, também, pelas dimensões sociais, produzidas pelas relações entre os indivíduos, como cultura, política e economia. As pessoas produzem espaços ao se relacionarem diversamente e são frutos dessa multidimensionalidade, por isso, o espaço geográfico contém todos os tipos de espaços sociais produzidos pelas relações entre as pessoas, e entre estas e a natureza, que provocam transformações, modificam as paisagens e constroem territórios, regiões e lugares. Portanto, a produção do espaço acontece por intermédio das relações sociais, no movimento da vida, da natureza e da artificialidade, principalmente no processo de construção do conhecimento, como afirma Fernandes (2006, p. 31-33). Tais características dos espaços desafiam os sujeitos que neles vivem e pretendem compreendê-los e, desta forma, as relações sociais entre os diferentes grupos, muitas vezes, realizam leituras e ações que fragmentam o espaço. São análises parciais, unidimensionais, setoriais, lineares, incompletas e, portanto, limitadas, porque necessitam delimitar. Essas leituras espaciais fragmentárias promovem desigualdades e diferentes formas de exclusão. Entendemos que o espaço é nomeado e classificado de acordo com os usos e ocupações atribuídos a ele e que estes têm relação com momentos específicos, portanto o tempo tem relação direta com a classificação e utilização do espaço.
} 
Figura 1 - Planta de uma residência ateniense: casa $C$ da ágora ateniense, século $V$ a.C.
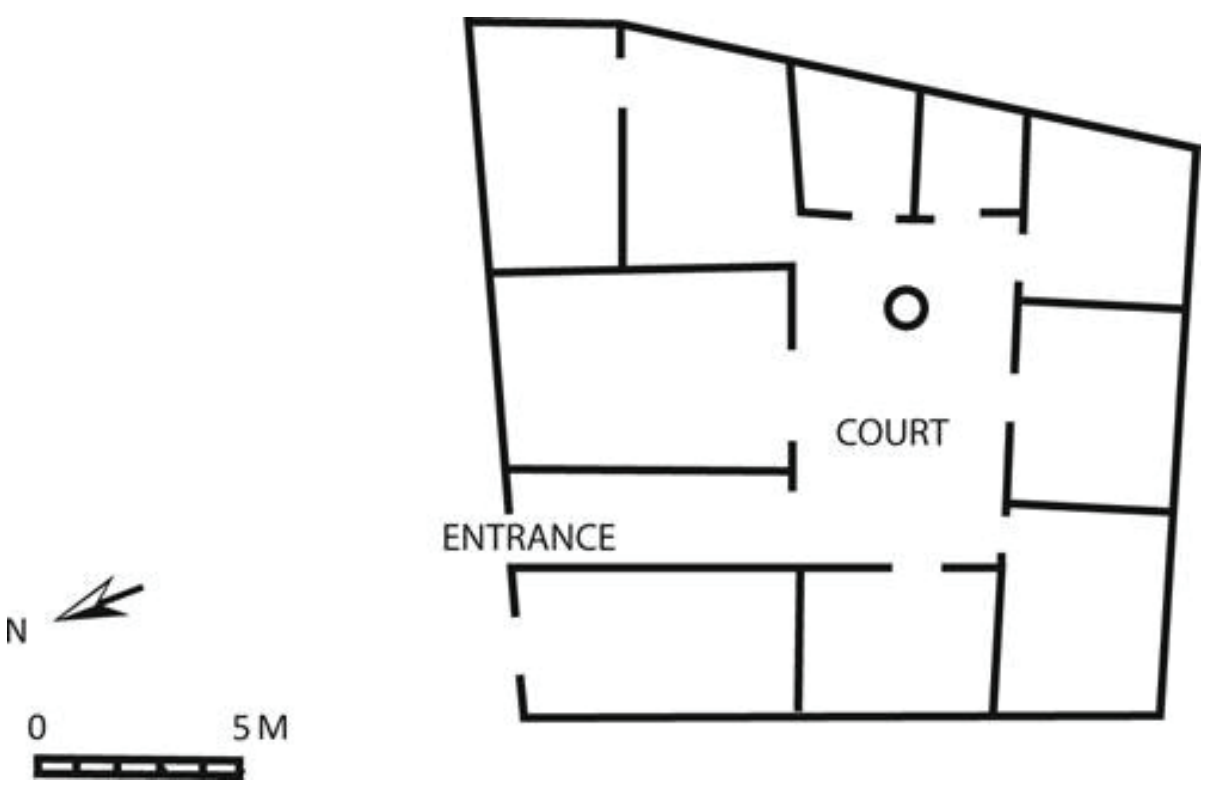

Fonte: Nevett (2010, p. 91, Fig. 3).

Aqui, temos o exemplo de uma residência que obedece a parâmetros extremamente similares aos mencionados, pois podemos ver que a maioria dos cômodos têm suas portas voltadas para um pátio central (e se interligam através dele), que leva a um corredor, sendo este o único meio de se chegar à passagem onde está a entrada principal da edificação. Cabe destacar que, paralelamente ao referido corredor, está posicionado o único cômodo que possui uma comunicação direta e independente com a rua, mas que, em contrapartida, de acordo com o que a planta mostra, não mantém qualquer ligação com os outros quartos da casa ou com o pátio central, indicando, talvez, que fosse o ândron - construído dessa maneira para manter os cômodos mais particulares da residência longe de olhares estranhos.

Desta forma, qualquer pessoa que quisesse entrar, sair, ou mesmo se locomover de um cômodo a outro da casa, faria isso sabendo que poderia estar sendo observada por outros. Cabe observar que em algumas casas havia andares superiores que não correspondiam a toda a extensão do primeiro andar. Contudo, faltam evidências para concluir se esses cômodos superiores possuíam janelas voltadas para o pátio interno ou para a porta de entrada da residência (NEVETT, 2010, p. 89).

Dependendo da topografia local, a entrada e talvez parte do pátio central de uma residência podem ter sido visíveis para vizinhos observando de seus próprios andares superiores ou de casas em partes mais altas da rua. Mesmo que as residências não possuíssem janelas voltadas para a rua, os telhados poderiam constituir locais de 
observação privilegiados (GRAHAM, 1998, p. 22-40). Considerar ou não como atitude adequada a uma mulher respeitável a prática de observar outras pessoas do telhado de uma residência pode ter dependido bastante do contexto social em que tal atividade era realizada. Observando as características físicas do ambiente arquitetônico de Atenas, podemos chegar à conclusão de que havia pouca chance de que alguém entrasse ou saísse de uma residência sem ser visto, fosse por outros habitantes da mesma casa ou por vizinhos (NEVETT, 2010, p. 90).

Lin Foxhall (2007, p. 233-242) defende que várias das atividades domésticas eram transportadas para diferentes espaços da casa, tanto diariamente - pois uma série de tarefas cotidianas, realizadas no mesmo espaço em horas diferentes do dia, ${ }^{2}$ era incompatível tanto em termos sociais como práticos -, como sazonalmente - os locais para realizar o cozimento dos alimentos e as práticas de tecelagem mudavam de acordo com as estações do ano. Além disso, é provável que as mulheres pudessem se locomover pelos espaços públicos com maior liberdade durante o dia, período em que os homens estariam ausentes do oîkos.

As ligações que foram expostas entre tempo e espaço tiveram papel preponderante no estabelecimento, implementação e permeabilidade dos limites impostos. Nas póleis, os limites estabelecidos podem ser exclusivamente físicos - como no caso da demarcação de propriedades -, mas também podem ser socialmente definidos, como era o caso do bairro do Kerameikos em Atenas, onde ficava o principal cemitério da pólis, e, também, era considerado o bairro da prostituição. Podemos observar ainda que, mesmo os limites físicos, como os de posse e direitos sobre alguma propriedade, não eram necessariamente absolutos (FOXHALL; NEHER, 2013, p. 8-9; HARDING, 2002, p. 558).

A grande variedade de status sociais (livre, liberto, escravo, cliente, fiador de dívidas, cidadão, etc.) colocados juntos no cenário urbano desorienta a noção de valor aplicada ao tempo gasto nas operações sociais, econômicas e políticas da pólis. As identidades - assim como o gênero - podem ser incorporadas temporariamente e depois mudadas. Outros fatores como a idade, estado marital, pertença à família, identidade étnica ou religiosa, ou mesmo a ocupação podem desempenhar um papel importante na compreensão de como as mulheres, como indivíduos ativos, escolheram ou foram capazes de pertencer às comunidades urbanas em que viviam (FOXHALL; NEHER, 2013, p. 9-13).

As relações sociais, mesmo que restringidas ou controladas por alguém, são um elemento comum a todos e constituem um componente vital para a vida de qualquer indivíduo pertencente a uma comunidade, independentemente de seu status social.

\footnotetext{
${ }^{2}$ Tarefas como a toalete, a tecelagem, atividades de preparo de alimentos, refeições, limpeza da residência, entre outras.
} 
Ao observarmos tais interações e analisarmos a variedade de redes sociais construídas por meio delas, será possível compreendermos a complexidade das relações sociais em Atenas. As relações sociais são pessoais e particulares, de acordo com as preferências e desejos de cada indivíduo, mas também são, ao mesmo tempo, alocadas em relação a um discurso social mais amplo e, em muitos casos, são projetadas na esfera pública.

Ultrapassar as noções de público e privado é importante para compreendermos os papéis femininos na pólis (BLOK, 2001, p. 7-40). ${ }^{3}$ A análise das redes sociais femininas e da forma como elas eram utilizadas tem o potencial de ultrapassar a visão tradicional de divisão exageradamente esquematizada (homens - público X mulheres - privado), e proporcionar uma perspectiva diferente acerca da realidade social, observando a atuação cívica e destacando os relacionamentos pessoais femininos.

Assim como os homens, as mulheres também estavam unidas entre si e com outros grupos por intermédio de redes baseadas nas relações de família, localidade, associações religiosas, atividades econômicas e daí por diante. Além disso, as relações fundamentadas em tais redes poderiam ser de longa ou de curta duração. Contudo, devemos ressaltar que nem sempre as mulheres conseguiam capitalizar recompensas por meio das redes em que estavam inseridas. Desta forma, é salutar investigarmos como as mulheres faziam uso de suas redes sociais e criavam algum capital social que pudesse ser aproveitado na esfera cívica.

Essas conexões poderiam ser concebidas como fortes ou fracas e, por isso, examiná-las torna possível distinguir os impactos que essas redes causavam sobre seus membros e a sociedade de forma mais ampla. Laços fortes, tais como entre familiares ou amigos próximos, claramente separam os membros de um grupo daqueles que não pertencem a ele. Ser admitido em um grupo pode ser encarado como uma situação muito especial e marcada por vários ritos sociais (por exemplo, as boas vindas dadas ao noivo ou à noiva em sua nova família durante a cerimônia de casamento). A ideia de pertencimento a esse tipo de grupo realiza um importante papel em moldar uma identidade grupal entre seus membros.

Esses laços internos servem para separar uns grupos dos outros (cada qual com sua identidade coletiva particular), mas também para ligá-los entre si por meio de laços fracos. Sejam mais fortes ou mais fracos, os laços podem ser rompidos de acordo com os problemas que os relacionamentos apresentarem, pois as pessoas podem brigar, morrer, se mudar, ou perder o interesse entre si. De tal modo, embora os laços fortes sejam

${ }^{3}$ Segundo Lessa (2001, p. 48-49), o discurso ideológico forjado pelos cidadãos atenienses pressupunha uma bipolaridade espacial restritiva, na qual os homens atuariam no exterior do oikos e as mulheres no interior. 
importantes para formar grupos coesos e mais exclusivos, é a presença ou a ausência de laços menos diretos que se tornam elementos chaves para a compreensão da estrutura da sociedade. A padronização das redes sociais pode criar um senso de solidariedade entre os membros, preencher os espaços que separam as pessoas, assim como alienar aqueles que estão de fora, permitindo que a mobilização de tais contatos possa ser utilizada para o bem ou para o mal.

$\mathrm{Na}$ estrutura específica da pólis, podemos considerar que os laços mais fortes fossem concebidos dentro do oikos (a unidade familiar), definindo aqueles que pertenciam a tal grupo e ao mesmo tempo separando-os dos que não pertenciam. O oîkos era uma parte fundamental da estrutura social, tanto que Aristóteles chegou a concluir que a pólis era a combinação dos diversos oîkoi. Mais que isso, o filósofo afirmava que as mulheres eram figuras centrais na dinâmica doméstica, de tal forma que, sem a sua presença não poderia haver oîkos (Aristóteles, Politica, 1252a24; 1253a24). A partir de tais formulações, podemos chegar à conclusão que sem as esposas e filhas de cidadãos atenienses não existiria Atenas, pois era função delas a preservação e a continuidade da unidade familiar e, consequentemente, da pólis.

Devemos observar, todavia, que as atenienses não são o único grupo preponderante para a existência e continuidade da pólis e nem o único grupo que circulava no espaço físico do oîkos. Além de esposas, filhos e filhas, parentes, escravos, o marido (cidadãos), amigos e amigas (sobretudo residentes na vizinhança) de um dos membros do oîkos, havia ainda um grupo que eventualmente - mesmo que de forma efêmera - seria convidado a adentrar o espaço doméstico: as hetaírai, ou seja, as cortesãs.

Assim como as esposas legítimas concediam aos seus maridos reconhecimento e prestígio diante da comunidade cívica, estar acompanhado por uma cortesã desejada e disputada também era digno de nota, pois tal atitude marcava uma prática identitária que separava os membros da elite daqueles que pertenciam a grupos menos abastados. É a partir desses conjuntos de relações pessoais e grupais que vai se construindo e reconstruindo a matriz feminina dentro dos espaços domésticos, que vão sendo utilizados, reutilizados e reclassificados de acordo com os momentos e funções a que são atribuídos.

A historiografia mais tradicional tendeu a defender a formulação de que, embora convivessem com os mesmos grupos de homens (os cidadãos atenienses), esposas legítimas e cortesãs recebiam educação e desenvolviam habilidades completamente diferentes. Dentro de tal linha de raciocínio, seria papel da esposa cuidar da família e conceber filhos, e suas maiores qualidades seriam a virtude e o recato; por outro lado, as cortesãs deveriam entreter e dar prazer, e seus principais atrativos seriam a beleza e 0 talento sexual. 
Entendemos que essas são conclusões muito simplificadas, unilaterais e unidimensionais, pois desconsideram toda a gama de relações sociais da qual já falamos. Parece que esposas e cortesãs, sejam como indivíduos ou como membros de grupos sociais, eram programadas para agir dentro de um número limitado de possibilidades, não importando a situação.

Entendemos que os objetivos e as funções das mulheres atenienses e das cortesãs, de fato, eram bastante distintos. Contudo, isso não quer dizer que elas não desenvolvessem qualidades similares, uma vez que conviviam com o mesmo grupo de homens. Nesse sentido, defendemos que diversos elementos das educações e das práticas cotidianas das esposas legítimas e das hetaírai se assemelhavam, embora buscando realizações diferentes.

Para tornar mais claras as ideias que defendemos, observemos a Figura 2, na qual temos uma pýxis de figuras vermelhas atribuída a Painter of the Louvre Centauromachy, em que sete mulheres estão agrupadas em duplas ou em trios. ${ }^{4}$

Figura 2 - Pýxis de figuras vermelhas atribuída a Painter of the Louvre Centauromachy

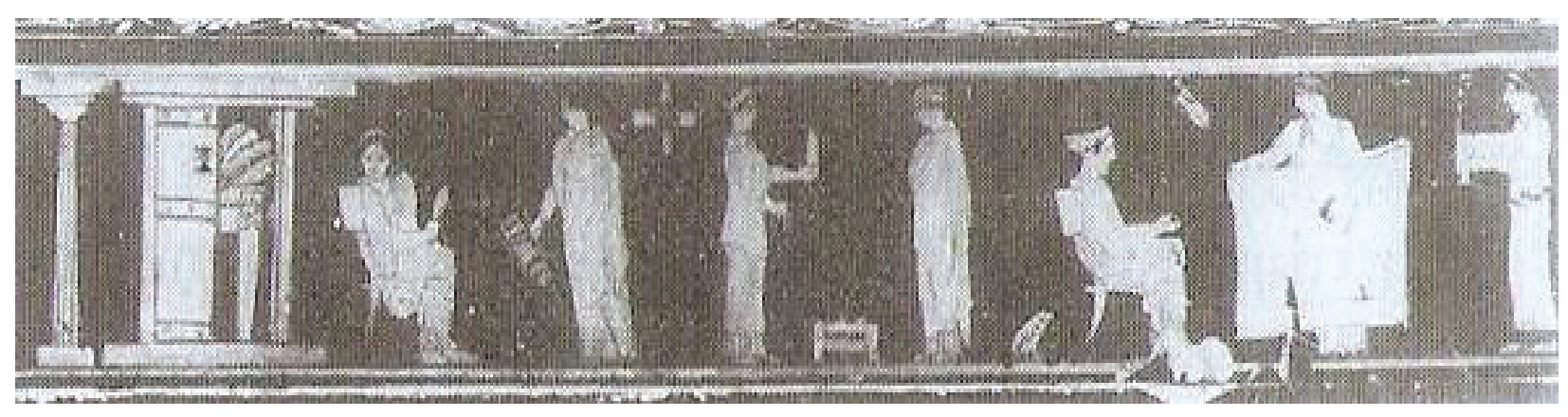

Localização: Paris, Louvre CA 587; Temática: gineceu; Proveniência: Ática; Forma: pýxis; Estilo: figuras vermelhas; Pintor: Painter of the Louvre Centauromachy; Data: ce. 450. Fonte: Brulé (2006, p. 168), Lessa (2001, capa) e Lewis (2002, p. 63, Fig. 2.1).

À direita da porta, a primeira mulher está sentada; sua face é vista frontalmente, voltando-se para o espectador da imagem; ela segura um objeto oval que pode ser uma roca ou um espelho. Diante dela, outra mulher segura um pequeno tear. O grupo seguinte está organizado em volta de um pequeno cofre de madeira que está no chão; a mulher da esquerda estende um alabástros àquela que está à sua frente. $\mathrm{O}$ último grupo, contendo três mulheres, se organiza em relação a uma mulher sentada que tem a mão esquerda levantada. Uma mulher dobra um grande tecido, enquanto que à sua direita há um cofre que pode servir para armazená-lo. Podemos observar ainda, na cena,

\footnotetext{
${ }^{4}$ A pýxis é uma pequena caixa cilíndrica com tampa. Servia como recipiente para cosméticos, incenso, joias ou unguentos medicinais; é considerado um vaso tipicamente feminino (CLARK et al., 2002, p. 134-137).
} 
um pequeno pássaro familiar, um vaso a despejar e um objeto em forma de cruz cujo contexto de uso não foi recuperado.

É difícil definir os vínculos sociais que existiam entre as personagens em cena. Contudo, podemos supor que esses vínculos pudessem ser de parentesco ou mesmo de amizade. Além disso, não devemos deixar de observar que as vestimentas (chíton plissado de cor clara) e os instrumentos de trabalho, como a roca, nos levam a acreditar que as personagens pertencem ao grupo das bem-nascidas. Ainda deve ser notado que a presença de uma coluna, do leito nupcial (thálamos), da mobília, do animal doméstico e dos objetos pendurados na parede evidenciam que a cena se desenrola no interior do oîkos.

O fato de todas as personagens na Figura 2 estarem dispostas em um mesmo plano pode denotar o pertencimento delas ao mesmo grupo social. É salutar observar que personagens e objetos aparentam atuar em um mesmo quadro espaço-temporal, explicitando o entrosamento necessário à realização de uma atividade conjunta. O gestual das personagens parece reforçar a sincronia necessária para o êxito das atividades em grupo.

Para contrapor a realidade sugerida pelas imagens do cotidiano doméstico das atenienses, apresentamos a Figura 3.

Figura 3 - Kýlix de figuras vermelhas de cerca de 500-450 a.C., atribuída a Makron

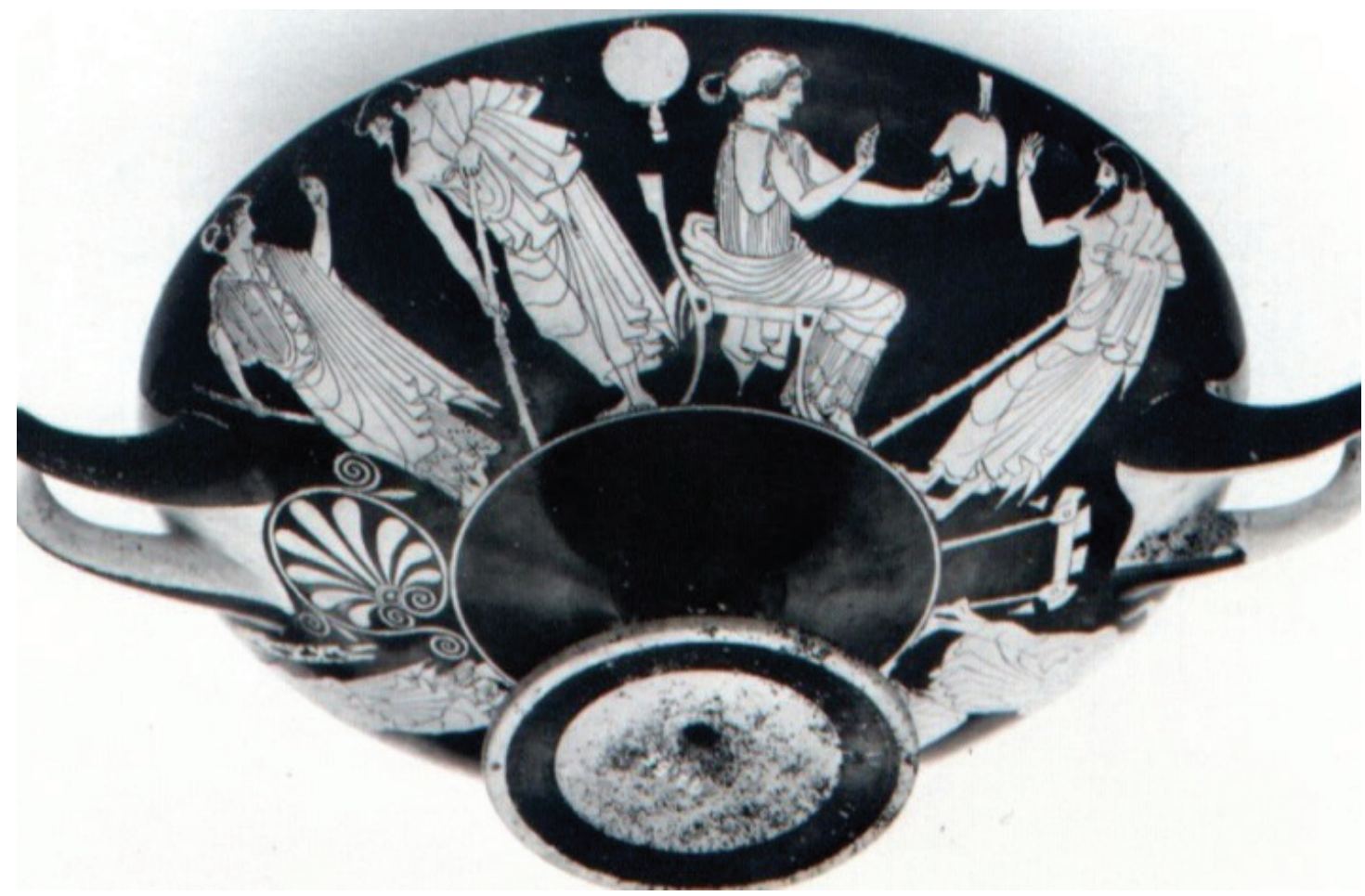

Localização: Toledo, Ohio, 72.55. Temática: negociação. Proveniência: não fornecida. Forma: kýlix. Estilo: figuras vermelhas. Pintor: Makron. Data: 500-450. Fonte: Keuls (1993, p. 167, Fig. 141 e 142). 
Aqui podemos ver uma das faces exteriores de uma kýlix de figuras vermelhas de cerca de 500-450 a.C., ${ }^{5}$ atribuída a Makron, onde há dois homens adultos (barba) apoiados em um cajado cada um, tentando persuadir duas hetaírai (uma sentada e a outra de pé). ${ }^{6}$ O da direita parece bem sucedido ao estender sua mão direita segurando uma flor e a mulher diante dele sorri e segura um ramo, o outro não parece ter tanta sorte. Dois signos devem ser destacados: a cadeira indica que a cena se desenrola no interior de uma residência (provavelmente das mulheres); os cajados indicam que os homens em cena são cidadãos atenienses.

As hetaírai - com todos os seus dotes artísticos e físicos - serviam aos cidadãos mais abastados (kaloí kagathoí) de Atenas. Elas eram mulheres livres, portanto com poder de escolha acerca de quem atenderiam e em troca do que (DAVIDSON, 1998, p. 124-126). Tomando como base tais informações, somos levados a pressupor que o contato com a hetaíra não seria uma transação comercial, mas uma troca de favores (ou presentes) entre as partes envolvidas, em que o sexo era um elemento implícito, mas não uma compensação imediata ou obrigatória. Esse sistema de boa-fé, baseado em reciprocidade e confiança, gerava relações mais longas entre as cortesãs e seus companheiros e, por isso, uma rede de clientes limitada, mas que, devido à proximidade entre os envolvidos, favorecia a maximização dos ganhos daquelas mulheres e da satisfação concedida aos seus amigos (BRULÉ, 2006, p. 208; DAVIDSON, 1998, p. 120-127). Independentemente de seu flutuante status econômico e social, que poderia sofrer grandes variações de acordo com as circunstâncias, as hetaírai se caracterizaram por sua participação no sympósion (CALAME, 2002, p. 116-117).

Além de belas, as cortesãs deveriam ser agradáveis, a educação delas era voltada ao mundo dos prazeres, visto que sua principal prerrogativa era divertir, entreter e dar prazer a seus clientes. A sedução era a principal arma que elas tinham para se inserir nos diálogos de poder junto aos cidadãos membros da elite ateniense.

Cabe ressaltar que o aprendizado das artes e subterfúgios da sedução não é um aspecto de domínio exclusivo das profissionais dos prazeres, pois o principal objetivo do casamento é a reprodução de herdeiros e a continuidade da pólis, o que só poderia acontecer por initermédio da prática sexual. Portanto, dominar as ferramentas que

\footnotetext{
${ }^{5}$ A kýlix é uma taça ampla em formato de tigela rasa com duas alças horizontais e suporte alto acima do pé. Era própria para o consumo do vinho (LESSA, 2001, p. 131). De acordo com Eva Keuls (1993, p. 165), a kýlix era a taça de beber mais característica dos sympósia.

${ }^{6}$ A identificação das mulheres como cortesãs se evidencia pela presença do aulós (flauta dupla ligada ao universo dos sympósia), que está na mão direita da primeira mulher da esquerda para a direita. O aulós reforça a presença do amor cortesão - envolvendo prazer e poder - entre um homem livre e uma personagem hierarquicamente inferior na sociedade, a hetaíra. Além disso, evidencia que esta deveria ser uma cortesã do mais alto nível, posto que as auletrídes (tocadoras de aulós) eram as mais caras e mais disputadas profissionais do prazer em Atenas (CERQUEIRA, 2000).
} 
manipulam a beleza e a sedução faz parte também das habilidades aprendidas pelas atenienses. Com Aristófanes, podemos ver que Lisístrata nos dá alguns dos inúmeros exemplos que permeiam a documentação textual:

\author{
Se ficássemos dentro de casa, maquiladas, e, sob as tunicazinhas de Amorgos, \\ nuas desfilássemos, o púbis depilado, \\ os maridos cheios de tesão, desejariam fazer sexo, mas se não nos aproximássemos, \\ se nos recusássemos, negociariam a trégua \\ rapidinho, sei bem disso \\ (Aristófanes, Lisístrata, 149-154). ${ }^{7}$
}

Além disso, ela ainda demonstra que não é apenas a beleza das esposas que seduz seus maridos, mas também a habilidade sexual que evidenciam: "Quando se voltam para a montaria, risco da lista os Cavaleiros, pois o mais hábil ginete e o que se mantem melhor montado é a mulher" (Aristófanes, Lisístrata, 676-677).

De acordo com Nidam-Hosoi (2007, p. 8-10), o discurso da iconografia ateniense apresenta um contexto em que a beleza masculina remete à virtude enquanto a beleza feminina remete à sedução e é manipulada por meio de subterfúgios (inclusive com as vestimentas). Podemos observar essa lógica operando, mesmo que de forma implícita, nas Figuras 2 e 3.

A presença da flor ou do perfume nas duas cenas marca uma transição da manipulação - mais óbvia - da aparência para a dos sentidos, pois a flor é um signo que remete ao perfume e, portanto, à sedução, mas também tem uma ligação simbólica com a bela jovem e o desabrochar da maturidade sexual, um momento efêmero para todas as mulheres (BODIOU; FRÈRE; MEHL, 2008, p. 151).

Ao aplicar o óleo perfumado em seu corpo, a mulher (esposa ou cortesã) torna-se mais atraente não apenas pelo odor e pela hidratação proporcionados por tal substância, mas também porque ela torna a pele brilhante e atrativa (BODIOU; FRÈRE; MEHL, 2008, p. 153-157). A utilização de tais téchnai tem influência no imaginário. Tudo isso se resume na seguinte passagem: "Isíade a de doce alento, mesmo que dez vezes cheires a perfume, desperta-te e recebe com tuas mãos queridas esta coroa, agora exuberante, mas que a aurora verás murcha, símbolo de tua juventude" (Antologia Palatina, V, 118).

Esta última citação evidencia um aspecto bastante característico da imagética ática, o de que a beleza é valorizada e, além disso, idealizada. As imagens de corpos jovens e

\footnotetext{
${ }^{7}$ Assim como a documentação textual, as imagens nos vasos destacam o apelo erótico e a necessidade estética da depilação feminina, sobretudo por meio das imagens em que ao menos uma das mulheres em cena é apresentada com a genitália numa disposição frontal convidando o olhar direto do espectador (KILMER, 1993, p. 104-112). Pierre Brulé (2006, p. 134-135) argumenta que a preferência da genitália depilada estaria relacionada ao ideal estético ligado a corpos jovens.
} 
esbeltos definem o ideal estético de beleza masculina e feminina nas representações iconográficas da Atenas do Período Clássico (BÉRARD, 2000, p. 392). As jovens são representadas como figuras magras, graciosas, com seios pequenos e firmes, com medidas muito parecidas com as masculinas, como se o artista utilizasse como modelo o corpo de um jovem rapaz adicionando os seios (FANTHAM et al., 1994, p. 116-118). De toda forma, a iconografia ática nos mostra que, enquanto a nudez masculina remetia à beleza e à força física do cidadão aristocrata, a nudez feminina era claramente erotizada. Por isso, o corpo feminino deveria se manter velado na esfera pública, uma vez que o poder erótico do nu feminino seria demais para o escrutínio público (GARRISON, 2000, p. 182-189).

Sendo assim, não nos parece surpresa o fato de que as cenas da imagética ática, que apresentam mulheres nuas ou que trazem inferências sexuais em relação a grupos femininos, se passem em espaços residenciais. Isso pode ser atestado ao observarmos a Figura 4, na qual vemos o medalhão interior (única parte decorada) de uma kýlix de figuras vermelhas de cerca de 510-500 a.C., atribuída a Gales Painter.

Figura 4 - Kýlix de figuras vermelhas de cerca de 510-500 a.C., atribuída a Gales Painter

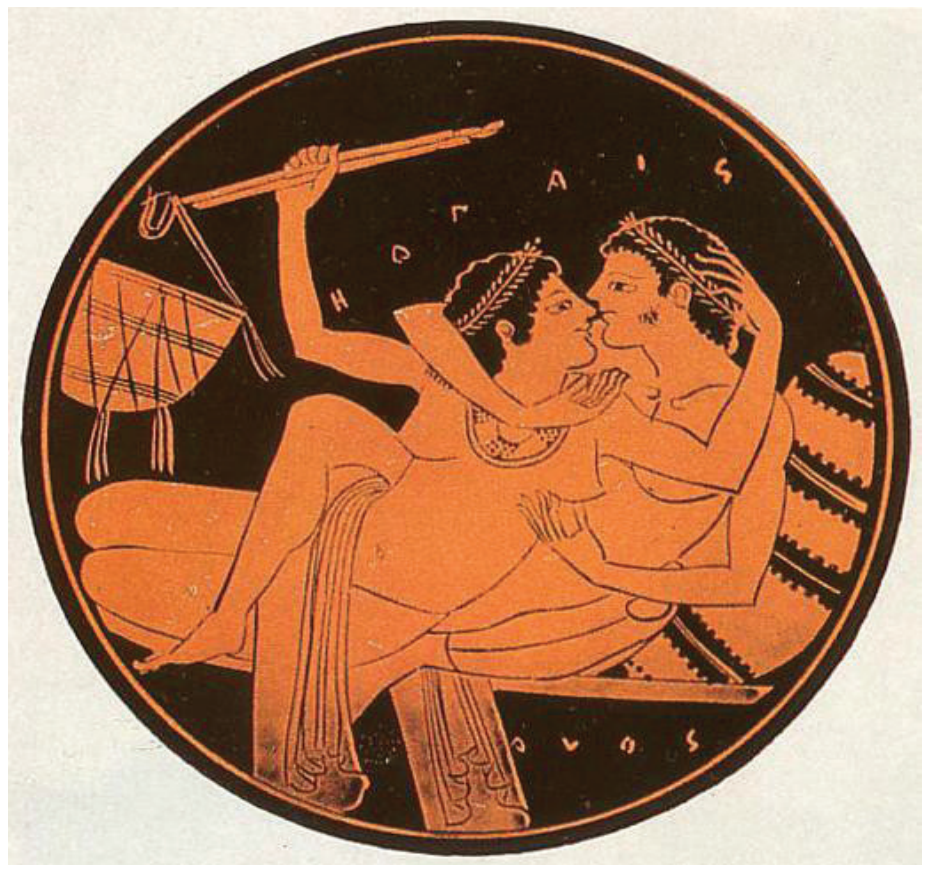

Localização: New Heaven, Yale University Art Gallery 1913.163. Temática: sympósion/prostituição. Proveniência: Etrúria, Vulci. Forma: kýlix. Estilo: figuras vermelhas. Pintor: Gales Painter. Data: 510-500. Fonte: Lewis (2002, p. 123, Fig. 3.24).

A cena mostra, da esquerda para a direita, uma hetaíra (com um aulós na mão direita) e um jovem rapaz (ausência de barba), ambos despidos e deitados sobre uma kliné, trocando carícias e aparentemente fazendo sexo. 
As cenas fazendo inferências aos atributos eróticos de esposas ou futuras esposas de cidadãos não eram tão explícitas como na Figura 4, pois, embora tivessem a intenção de demonstrar sua disponibilidade e atratividade sexual (com fins reprodutivos), deveriam manter uma imagem de respeitabilidade. ${ }^{8}$ Isso pode ser atestado pela Figura 5, na qual vemos o corpo de uma pýxis ática de figuras vermelhas, confeccionada por volta de 430-420 a.C., mostrando-nos as diversas etapas da preparação da noiva para a cerimônia do casamento.

Figura 5 - Corpo de uma pýxis ática de figuras vermelhas, confeccionada por volta de 430-420 a.C.

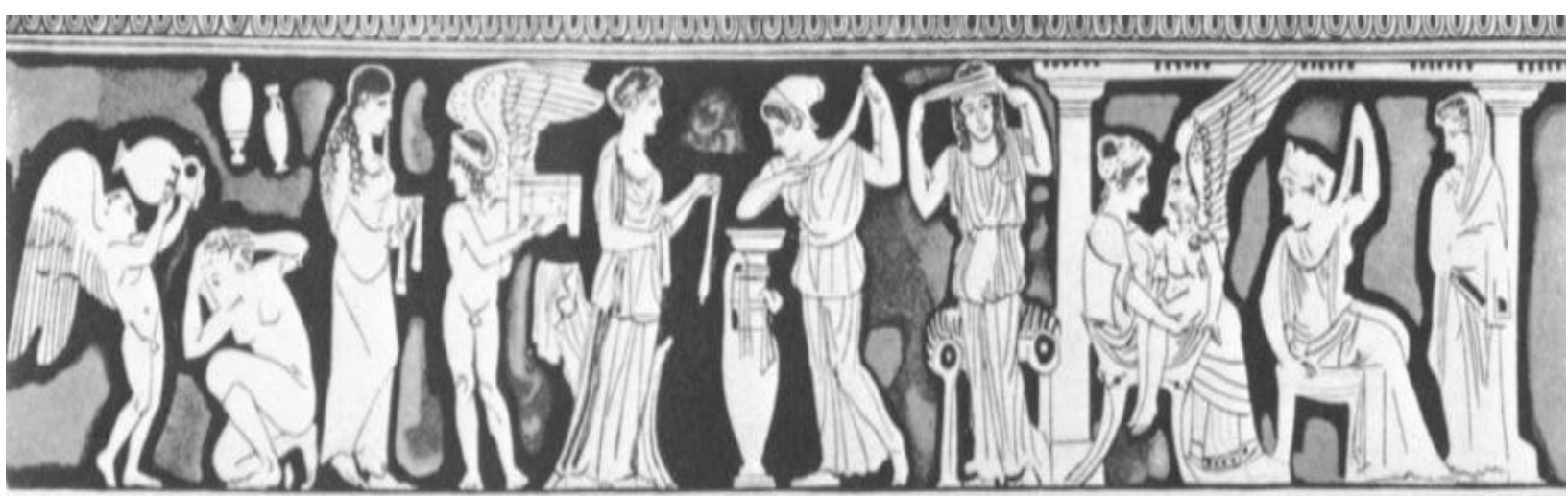

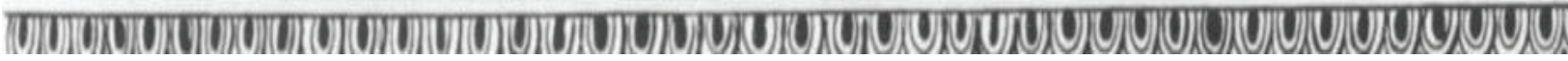

Localização: New York, Metropolitan Museum of Art 1972.118.148. Temática: toalete feminina/ preparação nupcial. Proveniência: não informada. Forma: pyxis. Estilo: figuras vermelhas. Pintor: não informado. Data: c. 425. Fonte: Oakley e Sinos (1993, p. 62, Fig. 20-1), Reilly (1989, pl. 78b) e Sutton Jr. (1992, p. 25, Fig. 1.9).

A cena se desenrola dividida em quatro momentos temporais distintos, "narrando" cada estágio da preparação da noiva, desde o banho nupcial até o aguardo para a saída da casa dos pais na procissão matrimonial rumo à casa do noivo.

Descreveremos a cena da esquerda para a direita: no primeiro estágio, temos uma mulher nua agachada (a noiva) diante de um pequeno Eros que derrama água sobre ela; no estágio seguinte, vemos a noiva atando sua cinta e segurando a ponta de seu chíton entre os dentes, reunindo bastante tecido para formar um kolpos (adorno em formato de sacola). Enquanto isso, vemos Eros, diante dela, segurando uma caixa; no grupo subsequente, vemos duas mulheres vestidas com peploi (vestidos tubulares longos usados por mulheres) amarrando fitas a um loutróphoros (vaso utilizado para o transporte

\footnotetext{
${ }^{8}$ Neste sentido, destacamos a Figura 2, que, ao mostrar a porta do quarto nupcial entreaberta, deixa claro que a prática do sexo faz parte da vida cotidiana de uma esposa legítima da mesma forma que a fiação e a tecelagem. Esse caráter sexual é reforçado por objetos como o vidro de perfume e o espelho, que aludem à manipulação e transformação do corpo feminino com o objetivo de seduzir.
} 
da água para o banho nupcial), enquanto uma terceira mulher (única personagem com posicionamento frontal - talvez a noiva) amarra uma faixa em volta da cabeça. Contudo, sua identidade é incerta; no último grupo, vemos a noiva sentada em uma cadeira vestindo chíton e himátion, com Eros sentado em seu colo, sendo observada por Afrodite (também sentada) e uma mulher de pé, cuja identidade é indeterminada (OAKLEY; SINOS, 1993, p. 16-17; REILLY, 1989, p. 421-422).

Podemos destacar a importância de certos signos, como a mobília e a coluna, que permitem a identificação da ambientação da cena em um espaço interior. Fica clara também a relação direta e indireta (por meio de Eros) ${ }^{9}$ entre Afrodite e a as núpcias, reforçando o apelo erótico exercido pela noiva e sua nudez. Devemos ressaltar também que a cena euforiza o caráter complementar atribuído às funções dos vasos nupciais, ${ }^{10}$ pois vemos o loutróphoros (onde a água foi transportada) e a hydría (sendo utilizada para banhar a noiva). ${ }^{11}$

Por tudo aquilo que vimos até aqui, fica claro que as atividades realizadas pelas personagens que compunham a matriz feminina eram muito mais multifacetadas e flexíveis do que os discursos elitistas (da documentação escrita) e o conservadorismo de obras historiográficas mais tradicionais queriam admitir. As imagens que decoram os vasos de figuras vermelhas nos revelam constantemente que, ao mesmo tempo que as esposas não se limitavam ao eterno recato e inocência (aprendendo a seduzir, dar e receber prazer), as cortesãs não eram prostitutas vulgares ou meras ferramentas de entretenimento, mas mulheres consideradas especiais em diversos sentidos.

A partir de tais constatações, devemos admitir que uma série de premissas que têm sido constantemente defendidas pela historiografia devem estar muito mais próximas de anseios vitorianos do que das práticas reais do cotidiano dos atenienses antigos. Portanto, devemos atravessar a porta do oikos em direção à rua, para que assim possamos ver o que aquelas mulheres faziam no seu dia-a-dia, nos espaços públicos da pólis, pois, embora a ágora possa ter sido dominada por homens, ela certamente não era um espaço exclusivamente masculino, uma vez que várias mulheres trabalhavam naquele lugar como comerciantes e em outros tipos de atividades. As mulheres também faziam uso das fontes

\footnotetext{
${ }^{9}$ Eros pode ser considerado como a representação do desejo humano pela imortalidade (SOULI, 1997, p. 18). Eros personifica o desejo que a noiva desperta em seu futuro marido (LEWIS, 2002, p. 144). Segundo Robert Sutton Jr (1992, p. 27), o Eros das cenas clássicas de casamento está especialmente associado à noiva, como uma força que ela emana, operando ativa e passivamente, expressando a emoção sentida pela noiva e a sensação que ela provoca no noivo.

${ }^{10}$ Os vasos utilizados na preparação para o banho nupcial eram dados de presente às noivas, sendo feitos em pares, o que reforçaria seu caráter complementar como parte de um conjunto matrimonial (OAKLEY; SINOS, 1993, p. 6-7).

${ }^{11}$ Vaso de corpo amplo e oval possuindo duas alças horizontais - destinadas a suspendê-la - e uma alça vertical com a função de pegá-la para despejar seu conteúdo. Como seu nome evidencia, a hydría era utilizada para transportar água (LESSA, 2001, p. 130; LEWIS, 2002, p. 214).
} 
públicas, muitas delas próximas à pnyx, o centro da vida política da pólis dos atenienses (VLASSOPOULOS, 2007, p. 33-43).

Foxhall e Neher (2013) defendem que a concentração de tantas atividades no espaço da ágora ou próximo a ele não acontecia por acaso e tinha o objetivo de representar que, tanto homens como mulheres, faziam parte da comunidade cívica, cada um à sua maneira. A pólis era uma comunidade fechada, numa cultura em que sua própria existência servia com a manifestação de uma unidade política superior. A construção do gênero era embasada na vida social e política daquela comunidade, estruturando desde as atividades cotidianas às instituições políticas mais abrangentes. A construção e o uso do espaço se entrelaçavam com os imperativos do gênero, de tal forma que a criação de ideologias e comportamentos genderizados moldava e era moldada pelo espaço concebido e pelo espaço físico da pólis (FOXHALL; NEHER, 2013, p. 16-17).

Ao analisar a genderização dos espaços cívicos da pólis, podemos concluir que as fontes de água eram um lugar central para a sociabilidade feminina, pois poderiam ser utilizadas para práticas rituais, fortalecimento de laços de parentesco e amizade, ou atividades corriqueiras do dia a dia (RAMSEY, 2013, p. 24).

Analisando o número de fontes de água conhecidas e observando a sua localização, temos a ideia de que pelos menos algumas delas forneciam água, sobretudo para o uso doméstico (NEVETT, 2010, p. 93). Tais argumentos podem ser reforçados com a análise da Figura 6, na qual podemos ver a combinação de dois tipos de atividades femininas fora do âmbito do oîkos, o abastecimento de água e a colheita de frutas.

Figura 6 - Pýxis de figuras vermelhas, de ce. 460 a.C., atribuída a Douris

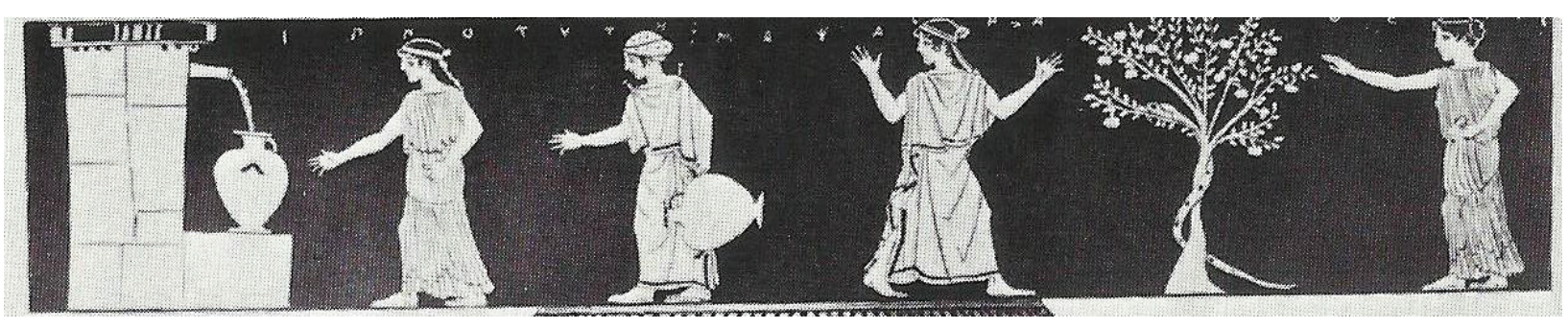

Localização: London, British Museum: E772. Temática: colheita de frutas e fonte. Proveniência: Atenas. Forma: pýxis. Estilo: figuras vermelhas. Pintor: Douris. Data: ce.460 a.C. Fonte: Lessa (2001, p. 98) e Lissarrague (1990, p. 243).

Nessa imagem, temos quatro personagens em cena, que estão de perfil, portanto sem comunicação direta com o espectador. Existem três signos que reforçam o caráter exterior da cena: a fonte, a árvore e a serpente (animal selvagem). Todas as personagens estão vestidas com o chitón, três delas usam cabelos amarrados por fitas e um com o 
sakkós. Segundo Lessa (2001, p. 98-99), os elementos em cena reúnem características suficientes para concluirmos que essas personagens representam o grupo das esposas bem-nascidas de cidadãos atenienses.

O peso de uma das hydríai carregadas na ágora, quando repleta de água, girava em torno de 16 kg (ROTROFF, LAMBERTON, 2006, p. 7). Portanto, carregar água não deveria ser uma tarefa tão agradável como as cenas presentes na iconografia parecem demonstrar em alguns momentos, por isso tais imagens trazem implicações sobre o status social das mulheres envolvidas. Podemos observar que, dentro de um discurso aristocrático, a documentação escrita nos informa que as fontes públicas eram lugares frequentados por escravas (Arist., Lis., 327-335). Heródoto, ao lembrar de tempos passados, fala das "jovens atenienses que iam buscar água na fonte do Enneakrounos - pois então não existiam escravos em Atenas, nem em lugar algum da Grécia" (Heródoto, História, VI, 137).

Assim, podemos imaginar que mulheres dos mais variados status sociais se encontrassem nas fontes, sendo que as mais abastadas estariam acompanhadas por suas escravas (que fariam o serviço pesado), enquanto que aquelas em condições financeiras menos favoráveis teriam que carregar seus próprios vasos cheios de água.

Além das idas à fonte, a documentação nos fornece uma série de exemplos de mulheres respeitáveis presentes nos espaços públicos da pólis, envolvidas em atividades do seu dia-a-dia e buscando colaborar com o sustento do oîkos a que pertenciam. Primeiro, Lisístrata, uma esposa legítima de cidadão ateniense e, portanto, uma mulher respeitável, convoca as mulheres aliadas, vendedoras de grãos, legumes, verduras, de alho, estalajadeiras e padeiras (Arist., Lis., 456-458). Em outra ocasião, uma das mulheres que celebram as Tesmofórias justifica o porquê de trabalhar no mercado, em contato com vários tipos de indivíduos:

\footnotetext{
O meu marido morreu em Chipre

me deixando cinco filhos pequenos e eu, com muita dificuldade, os alimentava, trançando coroas no mercado das flores,

Até então, bem ou mal, dava para comer,

mas agora, este daí, trabalhando nas tragédias, convenceu os homens de que os deuses não existem, de modo que não vendemos mais nem a metade.

[...] Mas vou-me embora para o mercado. Preciso trançar para uns homens vinte coroas de encomenda (Aristófanes, As Tesmoforiantes, 446-458).
}

Da mesma forma, uma vendedora de pães busca retribuição pelo prejuízo que o velho Bdelicléon havia Ihe causado:

Oh, lá está ele! [...]

Lá está o velho patife por quem fui usurpada, atingida por sua tocha, e que derrubou daqui 
pão no valor de dez óbolos, e quatro pãezinhos para servir (Aristófanes, As vespas, 1389-1392).

Todas essas passagens nos dão mostras de que era comum que mulheres respeitáveis em condições financeiramente desfavoráveis recorressem a atividades laborais, principalmente ligadas ao comércio, frequentando os espaços públicos da pólis em busca de melhores condições para si e suas famílias. A partir dessas informações, podemos analisar as imagens que se seguem.

Figura 7 - Peliké de figuras vermelhas produzida entre 470 e 460 a.C. e atribuída a Altamura Painter

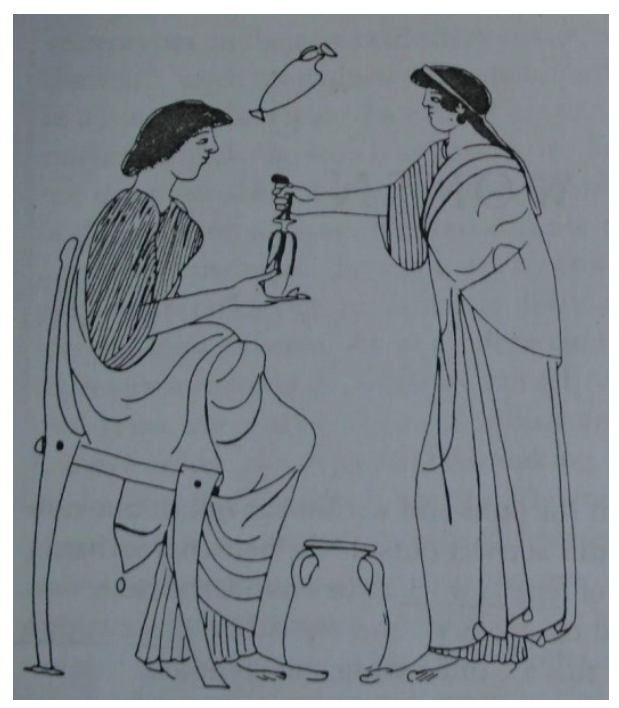

Localização: Berne, Historisches Museum: 12227. Temática: comércio/vendedora de perfumes. Proveniência: não fornecida. Forma: peliké. Estilo: figuras vermelhas. Pintor: Altamura Painter. Data: ce.470460 a.C. Fonte: Lewis (2002, p. 92, Fig. 3.1).

Na Figura 7, podemos ver a cena que decora uma peliké de figuras vermelhas produzida entre 470 e 460 a.C. e atribuída a Altamura Painter. ${ }^{12}$ Aqui, temos uma mulher sentada em uma cadeira que estende sua mão direita para receber um alabátros ${ }^{13}$ de outra mulher que está de pé à sua frente. Podemos destacar ainda a presença de uma peliké, no chão, entre as duas mulheres, e de um lékythos ${ }^{14}$ pendurado na parede, o que somado à presença da cadeira pode nos levar a concluir que essa cena se passa no

\footnotetext{
${ }^{12}$ O peliké é uma espécie de ânfora com o fundo largo e pesado cujo formato é aparentemente inspirado em recipientes feitos de peles de animais, como, por exemplo, odres para transportar vinho (LEWIS, 2002, p. 215).

${ }^{13} \mathrm{O}$ alabátros é um pequeno vaso, com embocadura achatada, pescoço estreito e corpo fino. Normalmente utilizado para o transporte de perfumes ou óleos aplicados à toalete feminina ou práticas cultuais (LESSA, 2001, p. 129).

${ }^{14} \mathrm{O}$ lékythos é um vaso com formato cilíndrico estreito e elevado, tendo um pé e uma única alça vertical, além de um pescoço estreito e embocadura pequena. Era usado para o transporte de óleos e unguentos, estando bastante relacionado ao contexto de rituais funerários, funcionando como oferenda (LESSA, 2001, p. 132; LEWIS, 2002, p. 215).
} 
interior de uma residência. Contudo, podemos levar em conta que as paredes externas de uma série de construções ao redor da ágora eram utilizadas por comerciantes de rua que procuravam se abrigar ali da ação do tempo e, ao mesmo tempo, colocarem suas mercadorias à disposição dos indivíduos que estivessem passando por ali. Assim, Sian Lewis (2002, p. 93) identifica que cenas como a da Figura 7 representariam o padrão iconográfico que remete à atividade comercial, com a vendedora sentada próxima aos objetos que está negociando e o cliente observando ou testando o produto.

Foi construída uma tradição historiográfica de relacionar cenas de negociação ou transação comercial entre mulheres e homens (evidenciadas pela presença de uma sacola de dinheiro) como sendo do universo da prostituição (NEILS, 2000; SUTTON JR., 1992; WILLIAMS, 1984). O paradigma tradicionalmente utilizado para relacionar cenas de negociação com o universo da prostituição se constrói a partir da justificativa de que as mulheres respeitáveis de Atenas não deveriam aparecer ou atuar sozinhas nos espaços públicos. Ora, como já vimos, a documentação nos concede uma série de exemplos inequívocos de que tanto as mulheres pobres quanto as bem-nascidas não permaneciam restritas ao interior do oîkos. A comédia aristofânica nos certifica da presença das mulheres no mercado de Atenas, vendendo desde produtos agrícolas a fitas e perfumes. Lessa (2001, p. 111-112) reforça ainda mais essa questão ao afirmar que as práticas sociais divergiam do modelo de comportamento ideal feminino, pois mesmo as bem-nascidas deixavam o gineceu em situações cotidianas, evidenciando uma permeabilidade mútua entre os espaços públicos e a vida doméstica, uma relação de complementaridade e não de oposição. ${ }^{15}$

Podemos considerar, então, que as interpretações acerca de cenas que trazem transações comerciais ou negociações entre homens e mulheres não têm sido tão precisas quanto deveriam. Se a presença de uma bolsa em uma cena de interação entre homem(s) e mulher(es) representa uma imagem de uma prostituta lidando com seu cliente, devemos nos perguntar o porquê de tantas outras cenas, também identificadas como de prostituição, desprezarem tal símbolo. Torna-se, assim, complicado acreditar que um elemento seja tão determinante e desnecessário ao mesmo tempo.

Os ideais de reclusão podem ter sido evocados para mulheres em estágios específicos de suas vidas. É possível imaginar, então, que atividades como a ida à fonte de água ou aos túmulos da família fossem empreendidas mais regularmente pelas garotas mais jovens e pelas mulheres mais velhas. Contudo, observamos que as esposas legítimas

${ }^{15}$ Rotroff e Lamberton (2006, p. 11) falam de uma ágora das mulheres (gynaikeia ágora), que seria especializada na venda de bens para a manutenção do lar e outros itens de interesse particular feminino. 
também poderiam lançar mão de certos subterfúgios para circular com liberdade pelas áreas mais públicas sem abandonar sua imagem de recato.

Para tanto, devemos imaginar a interseção das atividades desempenhadas pelos grupos masculinos e femininos nos espaços urbanos de Atenas. Levemos em conta que, em determinados períodos do dia, a maior parte dos cidadãos poderia estar longe da vizinhança em que moravam. Devemos considerar ainda que havia épocas do ano em que os homens se ausentavam por períodos mais longos, quando muitos deles viajavam para ajudar ou supervisionar as atividades em suas propriedades rurais, ou quando a pólis entrava em guerra. A presença massiva de mulheres na paisagem urbana em tais períodos deveria ser considerada, então, como algo comum (NEVETT, 2010, p. 99). De tal modo, concluímos que as associações do gênero com determinados espaços da pólis deveriam mudar de forma cíclica dentro de um quadro temporal relativamente curto.

Além disso, mesmo quando os homens estavam presentes de forma mais significativa, as mulheres poderiam encontrar estratégias adicionais para se locomoverem pelos espaços cívicos sem chamar muito a atenção, como, por exemplo, colocando vestimentas que cobrissem suas cabeças, ou mesmo véus escondendo seus rostos, o que pode ser corroborado pela documentação, como vemos na Figura 8 , em que está representada uma peliké de figuras vermelhas atribuída a Achilles Painter.

Figura 8 - Peliké de figuras vermelhas atribuída a Achilles Painter

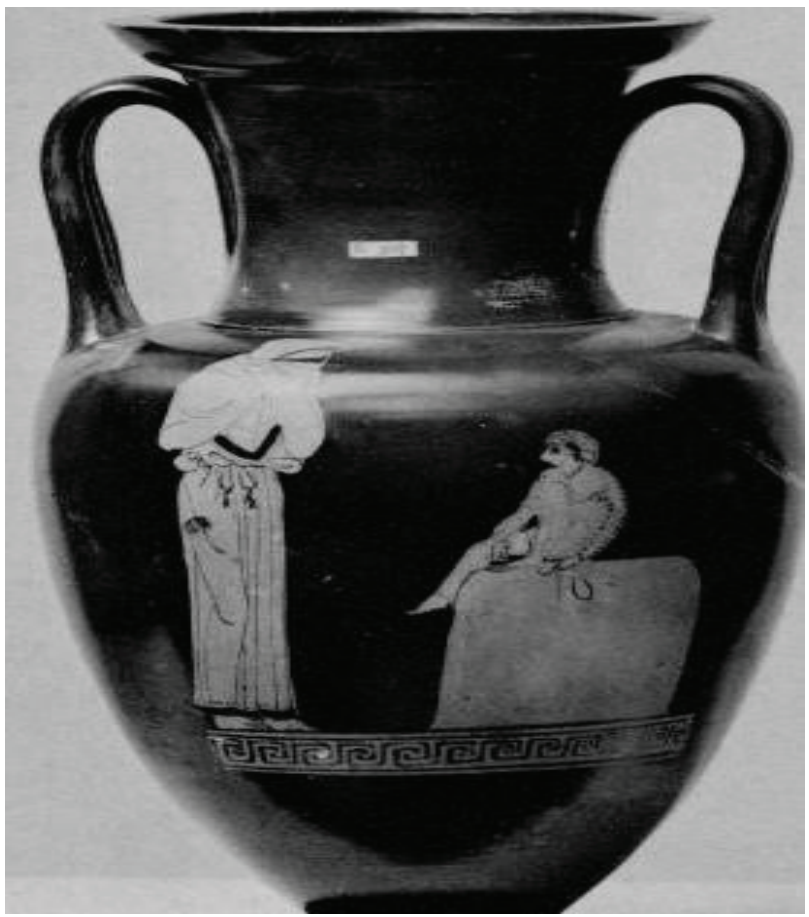

Localização: London, British Museum E307. Temática: colheita de frutas e fonte. Proveniência: Itália, Cápua. Forma: peliké. Estilo: figuras vermelhas. Pintor: Achilles Painter. Data: ce.475-425 a.C. Fonte: BAGPP 4707; CVA, LONDON, BRITISH MUSEUM 5, III.Ic.6, pl. (305) 55.1A-B. 
A cena pintada no corpo do vaso nos mostra uma mulher que está de pé e tem seu corpo completamente coberto pelas vestes. O véu que está usando deixa apenas seus olhos à mostra. À direita, diante da mulher, observamos um menino vestido de macaco sentado sobre um altar. O significado acerca da presença do menino é algo que nos escapa, contudo destacamos o fato de a mulher estar se encaminhando em direção a um local de culto, o que fazia parte das atividades cotidianas destinadas às atenienses. Não podemos deixar de apontar que a mulher está sozinha e talvez seja esse o motivo de tomar tanto cuidado em preservar sua identidade do escrutínio de olhares estranhos.

Essa prática pode ter sido considerada por alguns como uma infração em relação às liberdades concedidas às atenienses, pois tais objetos permitiam que elas circulassem pela pólis sem serem facilmente identificáveis, mas, como Llewellyn-Jones (2003, p. 189214) ressalta, isso possibilitava que mulheres casadas da elite pudessem ocupar os espaços cívicos da cidade, na presença de homens, sem provocar uma situação socialmente inaceitável. Presume-se ainda que essas mulheres estivessem acompanhadas por damas de companhia ou algum homem - familiar ou escravo. Os movimentos das mulheres formavam uma série de ciclos interligados e o caminho percorrido individualmente por cada uma delas através desses ciclos, assim como o uso do espaço cívico, eram moldados por uma série de fatores diferentes, como sua idade, status social e a riqueza de sua família. Pelo menos alguns dos espaços pelos quais as mulheres circulavam deveriam ter alguma flexibilidade quanto a sua relação com os padrões de gênero, e seriam classificados e reclassificados de acordo com fatores como a hora do dia, a época do ano e, de maneira mais direta, as identidades daqueles que ali estivessem presentes (NEVETT, 2010, p. 100).

O espaço cívico ateniense era um paralelo inverso dos espaços domésticos na pólis, que eram ideologicamente concebidos como um domínio do feminino, mesmo que, na realidade, também fossem lugares importantes para algumas atividades masculinas. Embora os limites e associações relacionados ao gênero apareçam de maneira bastante rígida na documentação escrita, na prática cotidiana perdiam sua clareza a partir dos comportamentos empreendidos pelos indivíduos. O direito de sair de suas residências com objetivo de realizar atividades específicas proporcionava às atenienses uma justificativa plausível para desafiar a ideologia cultural proposta por indivíduos da elite, fazendo da crítica à presença das mulheres nos espaços públicos algo característico dos registros escritos, enquanto que os pintores constantemente demonstram interesse por tais atividades (Aristófanes, $A$ paz, 981-982).

As redes sociais das quais as mulheres participavam concediam a elas a possibilidade de garantir o seu bem-estar assim como de contribuírem para a pólis como um todo. A análise dessas redes pode nos aproximar da compreensão daquilo que as mulheres 
poderiam fazer e ser, uma vez que elas permitiam aos grupos femininos a manipulação dos papéis que representariam, assim como assumir posições de liderança dentro de determinadas esferas e até mesmo da comunidade políade como um todo.

Por tudo isso, quando pensarmos na construção da pólis, devemos considerar as ações desempenhadas, nela, pelos grupos femininos. Reconhecer a contribuição feminina para a koinonía como algo em pé de igualdade com a atuação institucional masculina não é simplesmente desejável, mas uma necessidade. Só podemos compreender a vida cotidiana da Atenas Clássica se incluirmos nela a participação social e cívica dos grupos femininos.

Sendo assim, é imprescindível que voltemos os nossos olhares para as atividades femininas que ultrapassavam as práticas de manutenção e gestão do oîkos, de modo a compreender como e em que nível as personagens componentes da matriz feminina atuavam e contribuíam para a continuidade e manutenção da pólis como um todo. Além disso, é por intermédio de tal percepção que poderemos determinar que grupos femininos eram mais valorizados e respeitados por toda a comunidade políade e como eles aproveitavam esse reconhecimento em favor próprio.

\section{Referências}

\section{Documentação iconográfica}

BEAZLEY ARCHIVE: Greek painted pottery. Disponível em: <www.beazley.ox.ac.uk/ BeazleyAdmin/Script2/Pottery.htm>. Acesso em: 20 fev. 2015.

BEAZLEY, J. D. Attic red-figure vase painters. Oxford: Clarendon Press, 1963.

BOARDMAN, J. Greek sculpture. London: Thames and Hudson, 1995.

BOARDMAN, J. Athenian red figure vases. London: Thames and Hudson, 1997.

BOARDMAN, J. Athenian red figure vases: the classical period. London: Thames and Hudson, 1997.

\section{Documentação textual}

ARISTÓFANES. Lisístrata. Tradução de Ana Maria César Pompeu. São Paulo: Cone Sul, 1998.

ARISTÓFANES. As mulheres que celebram as Tesmofórias. Tradução de Maria de Fátima Silva. Lisboa: Edições 70, 2001.

ARISTÓFANES. Duas comédias: 'Lisístrata' e 'As Tesmoforiantes'. Tradução de Adriane da Silva Duarte. São Paulo: Martins Fontes, 2005. 
ARISTÓFANES. As rãs. As vespas. Tradução de Junito de Souza Brandão. Rio de Janeiro: Espaço e Tempo, s.d.

ARISTÓFANES. The Acharnians. The knights. The clouds. The Wasps. Translated by Benjamin

Bickley Rogers. Cambridge and London: Harvard University Press, 1992.

ARISTOTLE. The politics. In: ARISTOTLE. The politics and the Constitution of Athens. Translated by Jonathan Barnes. Cambridge: Cambridge University Press, 1996.

DEMÓSTENES. Contra-Neera. Madrid: Gredos, 1983.

DEMÓSTENES. Against Neaera. Cambridge: Harvard University Press, 1988.

EPIGRAMAS ERÓTICOS GRIEGOS. Antología palatina: Libros $V$ y XII. Traducción de

Guillermo Galán Vioque, Miguel A. Márquez Guerrero. Madrid: Alianza, 2005.

HERÓDOTO. História. Tradução de J. Brito Broca. São Paulo: Ediouro, 2001.

\section{Obras de apoio}

BÉRARD, C. The image of the other and the foreign hero. In: COHEN, B. (Ed.). Not the classical ideal: Athens and the construction of the other in Greek art. Leiden: Brill's Scholars' List, 2000, p. 390-412.

BLOK, J. H. Toward a coreography of women's speech in Classical Athens. In: LARDINOIS, A.; MCCLURE, L. (Ed.). Making silence speech: women's voices in Greek literature and society. Princeton: Princeton University Press, 2001.

BODIOU, L.; FRÈRE, D.; MEHL, V. Parfums et odeurs dans l'Antiquité. Rennes: Presses Universitaires de Rennes, 2008.

BRULÉ, P. Women of ancient Greece. Edinburgh: Edinburgh University Press, 2006.

CALAME, C. Eros en la Antigua Grecia. Madrid: Akal, 2002.

CERQUEIRA, F. V. A iconografía dos vasos gregos antigos como fonte histórica. História em Revista, v. 6, p. 85-96, 2000.

CLARK, A. J. et al. Understanding Greek vases: a guide to terms styles and techniques. Los Angeles: The J. Paul Getty Museum, 2002.

DAVIDSON, J. N. Courtesans and fishcakes: the consuming passions of Classical Athens. New York: St. Martin Press, 1998.

FANTHAM, E. et al. Women in Classical World: image and text. Oxford: Oxford University Press, 1994.

FERNANDES, B. M. Os Campos da pesquisa em educação do campo: espaço e território como categorias essenciais. In: MOLINA, M. C. (Org.). Educação do campo e pesquisa: questões para reflexão. Brasília: Ministério do Desenvolvimento Agrário, 2006, p. 27-39. 
FOXHALL, L. House Clearance: unpacking the "kitchen" in Classical Greece. In: WESTGATE, R.; FISHER, N.; WHITLEY, J. (Ed.). Building communities: house, settlement and society in the Aegean World and beyond. London: British School of Athens, 2007, p. 233-242.

FOXHALL, L.; NEHER, G. Introduction. In: FOXHALL, L.; NEHER, G. (Ed.). Gender and the city before Modernity. Oxford: Wiley-Blackwell, 2013, p. 1-19.

GARRISON, D. H. Sexual culture in Ancient Greece. Norman: University of Oklahoma Press, 2000.

GRAHAM, A. J. The woman at the window: observations on the 'Sstele from the Harbour' of Thasos. The Journal of Hellenic Studies, v. 118, p. 22-40, 1998.

HARDING, V. Space, property and propriety in urban England. Journal of Interdisciplinary History, v. 32, p. 549-69, 2002.

KEULS, E. C. The reign of Phallus: sexual politics in Ancient Athens. California: University of California Press, 1993.

KILMER, M. F. Greek erotica on Attic red-figure vases. London: Duckworth, 1993.

LESSA, F. S. Mulheres de Atenas: 'mélissa' do gineceu à ágora. Rio de Janeiro: Lhia, 2001.

LEWIS, S. The Athenian woman: an iconographic handbook. London: Routledge, 2002.

LISSARRAGUE, F. A figuração das mulheres. In: DUBY, G.; PERROT, M. (Ed.). História das mulheres no Ocidente: a Antiguidade. Porto: Afrontamento, 1990, p. 203-271. v. 1

LLEWELLYN-JONES, L. Aphrodite's tortoise: the veiled woman of Ancient Greece. London: Classical Press of Wales, 2003.

NEILS, J. Others within the other: an intimate look at hetairai and maenads. In: COHEN, B. (Ed.). Not the classical ideal: Athens and the construction of the other in Greek art. Leiden, Boston, Köln: Brill's Scholars' List, 2000, p. 203-226.

NEVETT, L. C. Domestic spaces in Classical Antiquity. Cambridge: Cambridge University Press, 2010.

NIDDAM-HOSOI, N. Des femmes au louterion: a la croisée d'une esthètique masculine et feminine au travers des objets. Images Re-vues, v. 4, p. 1-11, 2007.

OAKLEY, J. H.; SINOS, R. H. The wedding in Ancient Athens. Madison; London: The University of Wisconsin Press, 1993.

RAMSEY, G. Royal female intervention and patronage in Hellenistic civic communities. In: FOXHALL, L.; NEHER, G. (Ed.). Gender and the city before Modernity. Oxford: WileyBlackwell, 2013, p. 21-37.

REILLY, J. Many brides: "mistress and maid" on Athenian Lekythoi. Hesperia, v. 58, n. 4, p. 411-444, 1989. 
ROTROFF, S. I.; LAMBERTON, R. D. Women in the Athenian agora. Athens: American School of Classical Studies, 2006.

SOULI, S. A. The love life of the Ancient Greeks. Athens: Editions Michalis Toubis, 1997.

SUTTON JR., R. Pornography and persuasion on Attic pottery. In: RICHILIN, A. Pornography and representation in Greece and Rome. New York, Oxford: Oxford University Press, 1992, p. 3-35.

VLASSOPOULOS, K. Free spaces: identity, experience and democracy in Classical Athens. Classical Quarterly, v. 57, n. 1, p. 33-52, 2007.

WILLIAMS, D. Women on Athenian vases: problems of interpretation. In: CAMERON, A.; KUHRT, A. (Ed.). Images of women in Antiquity. London: Croom Helm, 1984, p. 92106. 